\author{
INEEL/CON-02-00574 \\ PREPRINT
}

\title{
Oxygen Reactivity of a Carbon Fiber Composite
}

\author{
T.D. Marshall, R.J. \\ Pawelko, R.A. Anderl, \\ G.R. Smolik, B.J. Merrill, \\ R.L. Moore, D.A. Petti
}

\section{September 2002}

\section{$22^{\text {nd }}$ Symposium on Fusion Technology}

This is a preprint of a paper intended for publication in a journal or proceedings. Since changes may be made before publication, this preprint should not be cited or reproduced without permission of the author.

This document was prepared as an account of work sponsored by an agency of the United States Government. Neither the United States Government nor any agency thereof, or any of their employees, makes any warranty, expressed or implied, or assumes any legal liability or responsibility for any third party's use, or the results of such use, of any information, apparatus, product or process disclosed in this report, or represents that its use by such third party would not infringe privately owned rights. The views expressed in this paper are not necessarily those of the U.S. Government or the sponsoring agency. 


\title{
Oxygen Reactivity of a Carbon Fiber Composite
}

\author{
T.D. Marshall, R.J. Pawelko, R.A. Anderl, G.R. Smolik, \\ B.J. Merrill, R.L. Moore, D.A. Petti \\ Idaho National Engineering and Environmental Laboratory \\ P.O. Box 1625, Idaho Falls, ID 83415-3860 USA
}

\begin{abstract}
Carbon Fiber Composites (CFCs) are often suggested as armor material for the first wall of a fusion plasma chamber due to carbon's low atomic number, high thermal conductivity, and high melting point. However, carbon is chemically reactive in air and will react with ingress air during a Loss of Vacuum Accident and release tritium fuel that has been retained in the carbon. Tritium mobilization and carbon monoxide generation via CFC oxidation are both safety concerns.

This paper discusses chemical reactivity experiments that were performed using the state-ofthe-art 3-dimensional NB31 CFC and a laminar reaction gas of $\mathrm{Ar}-21 \mathrm{vol} \% \mathrm{O}_{2}$. Oxidation reaction rates were measured for $\mathrm{CFC}$ temperatures of $525,600,700,800,900$, and $1000{ }^{\circ} \mathrm{C}$ and a 100 standard cubic centimeters per minute $(\mathrm{sccm}) \mathrm{Ar}-\mathrm{O}_{2}$ flow rate. Experiments were also performed at $\mathrm{CFC}$ temperatures of 700 and $1000{ }^{\circ} \mathrm{C}$ and a $1000 \mathrm{sccm} \mathrm{Ar}-\mathrm{O}_{2}$ flow rate. Mass spectral analyses of the exhaust reaction gas suggested that carbon monoxide was the primary reaction at the CFC surface and carbon dioxide was readily produced in the exiting reaction gas. The measured reaction rates compare well with the literature and were used to produce a CFC oxidation curve that is recommended for use in fusion safety analyses.
\end{abstract}

Keywords: CFC oxidation, carbon oxidation, oxidation experiment

\section{Introduction}

Literature [1] on the chemical reactivity of carbon suggests four potential chemical reactions between carbon and oxygen, as presented in Table 1. 
Table 1. Chemical reactions between carbon and oxygen.

\begin{tabular}{||l|c|}
\hline \multicolumn{1}{|c|}{ Reaction } & Free Energy (kcal) \\
\hline $\mathrm{C}(\mathrm{s})+\mathrm{O}_{2}(\mathrm{~g})=\mathrm{CO}_{2}(\mathrm{~g})$ & -94.03 \\
\hline $\mathrm{C}(\mathrm{s})+\frac{1}{2} \quad \mathrm{O}_{2}(\mathrm{~g})=\mathrm{CO}(\mathrm{g})$ & -26.62 \\
\hline $\mathrm{CO}(\mathrm{g})+\frac{1}{2} \quad \mathrm{O}_{2}(\mathrm{~g})=\mathrm{CO}_{2}(\mathrm{~g})$ & -67.41 \\
\hline $\mathrm{C}(\mathrm{s})+\mathrm{CO}_{2}(\mathrm{~g})=2 \mathrm{CO}(\mathrm{g})$ & +40.79 \\
\hline Note: & $\begin{array}{l}(\mathrm{s})=\text { solid; }(\mathrm{g})=\text { gas; } \mathrm{CO}=\text { carbon } \\
\text { monoxide; } \\
\mathrm{CO}_{2}=\text { carbon dioxide }\end{array}$ \\
\hline
\end{tabular}

The amount of carbon oxidized during the reactions in Table 1 and the amount of the product gases are highly dependent upon: oxygen concentration and flow rate, oxygen turbulence at the surface layer, and reaction temperature [2].

The negative free energies listed in Table 1 indicate that the reactions are chemically favorable. Accordingly, the free energy data in Table 1 suggest that the primary reaction of a CFC exposed to oxygen gas should produce carbon dioxide $\left(\mathrm{CO}_{2}\right)$ and carbon monoxide $(\mathrm{CO})$. Thus, it was deemed important to measure the $\mathrm{CO}$ and $\mathrm{CO}_{2}$ produced during the $\mathrm{CFC}$-air chemical reactivity experiments.

Experiments on the chemical reactivity of carbon in an oxygen flow stream were previously performed by the Idaho National Engineering Laboratory (INEL) in 1988 [3]. Those experiments studied Union Carbide bulk graphite, FMI carbon-carbon composite graphite, and Pfizer pyrolytic graphite. The temperature range of those experiments was 800 to $1800{ }^{\circ} \mathrm{C}$. The chemical reactivity experiments discussed here extend the 1988 data by using NB31, a state-of-the-art CFC frequently suggested for fusion applications, as the test specimen and testing over a temperature range of 525 to $1000{ }^{\circ} \mathrm{C}$. 


\section{Fundamentals of carbon oxidation}

In 1956, Rossberg and Wicke [4] performed graphite oxidation experiments and obtained results that suggested three discrete reaction regimes. These regimes are applicable for reactions between gases and porous solids with exclusively gaseous products [5].

Figure 1 illustrates the three kinetic regimes of chemical kinetic control (Regime I), in-pore diffusion of oxygen (Regime II), and boundary layer diffusion (Regime III). At low CFC temperatures, Regime I, the oxidizing gas homogeneously reacts with the porous CFC. Mass transport rates are more rapid than chemical reaction rates and an uniform oxidation occurs throughout the CFC. This regime involves chemisorption, chemical reaction, and desorption from internal surfaces; Regime I is uniquely controlled by the intrinsic chemical reactivity of the CFC.

Regime II oxidation occurs at a higher temperature than Regime I and features a heterogeneous reaction rate comprised of both surface chemical reaction and in-pore diffusion. Regime II is reported to have a lower temperature dependency than Regime I [6].

Regime III oxidation occurs at such a high temperature that the carbon is extremely reactive and thus the reaction rate is uniquely controlled by the oxygen mass transfer rate to the CFC surface. The oxygen mass transfer rate is strongly influenced by the nature of the gas at the CFC surface. For laminar flow, the mass transfer coefficient is dependent upon the diffusion coefficient [5], which increases with temperature to the 1.5 power [7]. 


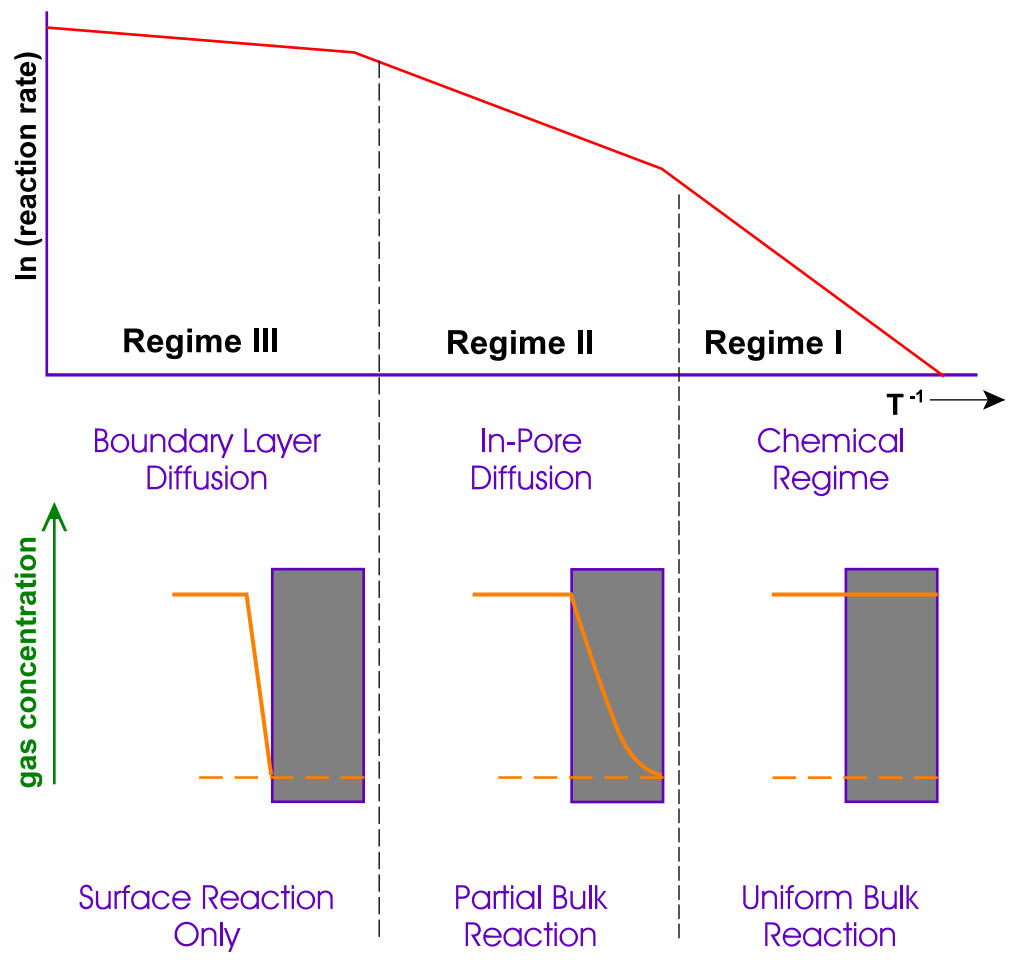

Figure 1. Schematic model of reactions between gases and porous CFC with exclusively gaseous products.

\section{Test Specimen}

NB31 [8] is an advanced, high thermal conductivity carbon fiber composite (CFC) that was manufactured by the Société Européenne de Propulsion and DUNLOP. An approximate density of $1.91 \mathrm{~g} / \mathrm{cm}^{3}$ was created by the processes of: (1) chemical infiltration of pyrocarbon at $1000{ }^{\circ} \mathrm{C},(2)$ heat treatment at $2800{ }^{\circ} \mathrm{C}$, (3) a second chemical infiltration of pyrocarbon at $1000{ }^{\circ} \mathrm{C}$, and (4) a pitch impregnation at $100 \mathrm{MPa}$ and $1000{ }^{\circ} \mathrm{C}$. The dimensions of the test specimen were nominally $2.5 \times 0.8 \times 0.4(\mathrm{~L} \times \mathrm{W} \times \mathrm{D}) \mathrm{cm}$.

\section{Experiment System}

The Idaho National Engineering and Environmental Laboratory (INEEL) Steam Reactivity Measurement System was originally assembled to measure hydrogen generation and tritium mobilization rates during steam interactions with irradiated beryllium [9]. For the CFC oxidation 
experiments, the system was modified as shown in Figure 2. A reaction gas of Ar- $21 \mathrm{vol} \% \mathrm{O}_{2}$ was used instead of ambient air because the $\mathrm{N}_{2}$ gas in ambient air produces a mass signal of 28 on the mass spectrometer and would thereby mask the CO mass signal of 28.

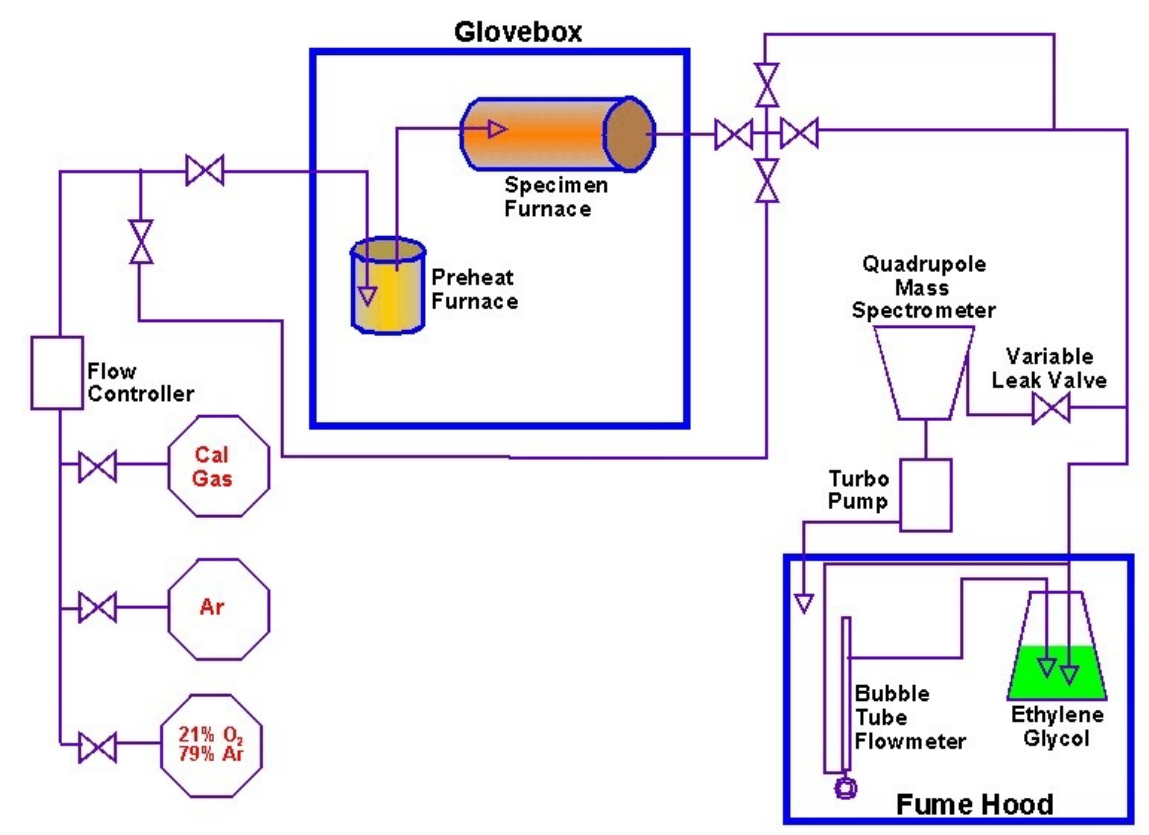

Figure 2: Schematic of INEEL chemical reactivity measurement system.

\section{Experiment Procedure}

The specimen was ultrasonically cleaned under inert gas, then weighed and installed in a quartz glass reaction chamber [10]. High purity Ar was circulated to purge the system of air and a quadropole mass spectrometer(QMS) sampled the exhaust Ar to verify that the system was without leaks. A tube furnace heated the quartz reaction chamber to the desired temperature and Ar- $\mathrm{O}_{2}$ flowed through a pre-heater and into the quartz reaction chamber. The QMS measured the production of $\mathrm{CO}$ and $\mathrm{CO}_{2}$ for the duration of the experiment. The reacted specimen was subsequently removed, weighed, and stored. The QMS provided $\mathrm{CO}$ and $\mathrm{CO}_{2}$ concentration data as a function of reaction time, hence, those data provided kinetic information on $\mathrm{CO}$ and $\mathrm{CO}_{2}$ generation rates. Integration of the QMS data yielded the total quantity of $\mathrm{CO}$ and $\mathrm{CO}_{2}$ generated 
while measurements of the specimen weight loss and the reaction time provided a determination of the oxidation rate.

\section{Experiment Results}

\section{$6.1 \mathrm{CO}$ and $\mathrm{CO}_{2}$ Generation Rates}

As a result of the low flow rate for the $\mathrm{Ar}-\mathrm{O}_{2}$ reaction gas, $\mathrm{CO}_{2}$ was produced by the unconsumed $\mathrm{O}_{2}$ reacting with the $\mathrm{CFC}$ surface-generated $\mathrm{CO}$ as the reaction gas exited the reaction chamber. The phenomenon explains the large amount of $\mathrm{CO}_{2}$ measured during the experiment, see Table 2.

Table 2. $\mathrm{CO}$ and $\mathrm{CO}_{2}$ data from NB31 chemical reactivity experiments.

\begin{tabular}{|c|c|c|c|c|c|c|c|}
\hline \multirow[b]{2}{*}{ Specimen } & \multirow{2}{*}{$\frac{\text { Temp }}{\left({ }^{\circ} \mathrm{C}\right)}$} & \multicolumn{2}{|c|}{ C consumed } & \multicolumn{2}{|c|}{ CO produced } & \multicolumn{2}{|c|}{$\mathrm{CO}_{2}$ produced } \\
\hline & & $(\mathrm{mg})$ & (moles) & $\left(\mathrm{std} \mathrm{cm}^{3}\right)$ & (moles) & $\left(\mathrm{std} \mathrm{cm}^{3}\right)$ & (moles) \\
\hline \multicolumn{8}{|c|}{100 std $-\mathrm{cm}^{3}$ Ar- $\mathrm{O}_{2}$ Flow Rate } \\
\hline NB31-08 & 525 & 4.1 & 0.0003 & 7.4 & 0.0003 & 9.2 & 0.0004 \\
\hline NB31-02 & 601 & 30.6 & 0.0026 & 15.5 & 0.0007 & 68.2 & 0.0030 \\
\hline NB31-01 & 705 & 663.2 & 0.0552 & 334.2 & 0.0149 & 1202.9 & 0.0537 \\
\hline NB31-04 & 815 & 356.2 & 0.0297 & 3.7 & 0.0002 & 828.4 & 0.0370 \\
\hline NB31-05 & 919 & 165.6 & 0.0138 & 2.8 & 0.0001 & 394.9 & 0.0176 \\
\hline NB31-03 & 1016 & 92.1 & 0.0077 & 0.0 & 0.0000 & 231.4 & 0.0103 \\
\hline \multicolumn{8}{|c|}{1000 std-cm ${ }^{3} \mathrm{Ar}-\mathrm{O}_{2}$ Flow Rate } \\
\hline NB31-09 & 705 & 71.1 & 0.0059 & 39.0 & 0.0017 & 112.1 & 0.0050 \\
\hline NB31-06 & 1054 & 344.7 & 0.0287 & 4.7 & 0.0002 & 730.0 & 0.0326 \\
\hline \multicolumn{8}{|c|}{3 std-cm ${ }^{3} \mathrm{Ar}-\mathrm{O}_{2}$ Flow Rate } \\
\hline NB31-07 & 705 & 115.0 & 0.0096 & 4.7 & 0.0002 & 249.6 & 0.0111 \\
\hline
\end{tabular}




\subsection{Reaction Rates}

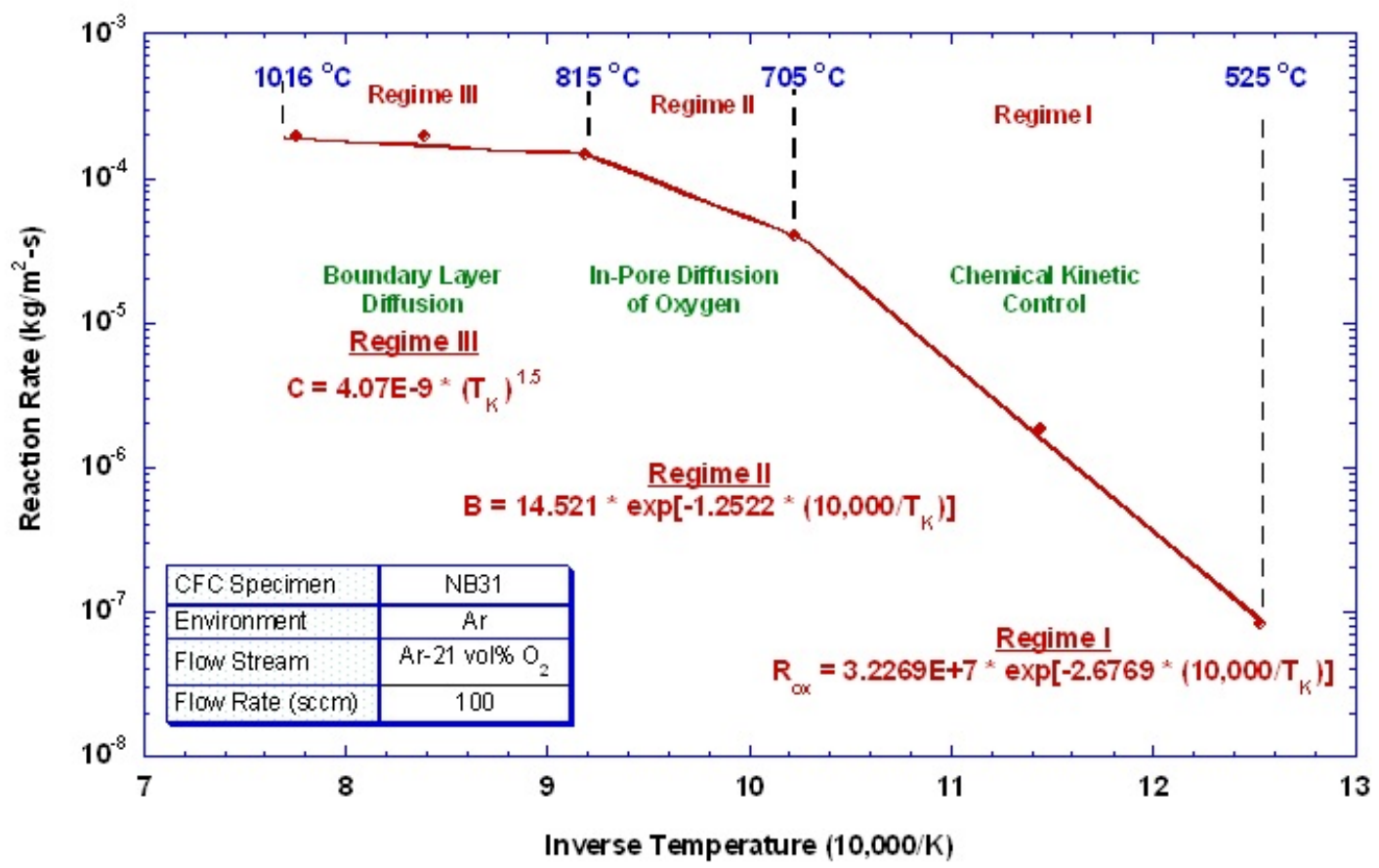

Figure 3. Experiment reaction rates with curve fit and identification of oxidation regimes.

The calculated reaction rates, defined as CFC weight loss $(\mathrm{kg})$ divided by the product of the CFC geometric surface area $\left(\mathrm{m}^{2}\right)$ and the oxidation time $(\mathrm{s})$, are presented in Figure 3 . The three regimes of oxidation were identified using the change in slope for the linear curve fits applied to the experiment data.

\subsection{Integrated Reaction Rates}

Integration of the previous INEL carbon oxidation experiments with the current experiment data produces a CFC oxidation curve that is recommended for use in fusion safety analyses:

Regime I: $\left[525 \leq \mathrm{T}<710{ }^{\circ} \mathrm{C}\right]$

$$
R_{\text {Ox }}=1.4754 \times 10^{7} \cdot \exp \left[-2.6128 \cdot \frac{10000}{T_{K}}\right]
$$


Regime II: $\left[710 \leq \mathrm{T}<1175^{\circ} \mathrm{C}\right]$

$$
R_{o x}=36.308 \cdot \exp \left[-1.3475 \cdot \frac{10000}{T_{X}}\right]
$$

Regime III: $\left[1175 \leq \mathrm{T}<1720{ }^{\circ} \mathrm{C}\right]$

$$
R_{o x}=1.57 \times 10^{2} \cdot \exp \left[-0.226 \cdot \frac{10000}{T_{X}}\right]
$$

\subsection{Conclusions}

Oxidation experiments with the NB31 state-of-the-art CFC were performed to supplement previous oxidation data. The new data exhibited the traditional three regimes of oxidation, and when integrated with the previous data, produced an oxidation curve that should adequately predict CFC oxidation in the first wall of a fusion plasma chamber.

\subsection{References}

1. Advances in Catalysis and Related Subjects, Volume XI, Academic Press Inc., 1959, pp 133-217.

2. L. Snead and T. Burchell, "Oxidation of High-Quality Graphite for IFE," Proceedings of the DOE/NE High Average Power Laser Program Workshop, Pleasanton, CA, July $25-26,2002$.

3. M.H. O'brien, B.J. Merrill, and S.N. Ugaki, Combustion Testing and Thermal Modeling of Proposed CIT Graphite Tile Materials, INEL, EGG-FSP-8255, 1988.

4. M. Rossberg and E. Wicke, "Transportvorgänge und Oberflächenreaktionen bei der Verbrennung graphitischen Kohlenstoffs," Chemie-Ingenieur-Technik, 3, pp 181-189, 1956.

5. R. Moormann, "Graphite Oxidation Phenomena During Massive Air Ingress Accidents in Nuclear High Temperature Gas Cooled Reactors with Pebble Bed Core," Berichte der Bunsen-Gesellschaft fur Physikalische Chemie, 87, 11, 1983, pp 1086-1090.

6. R.P. Wichner and S.J. Ball, Potential Damage to Gas-Cooled Graphite Reactors Due to Severe Accidents, ORNL/TM-13661, Oak Ridge National Laboratory, 1999, Appendix A. 
7. J.R. Welty, C.E. Wicks, R.E. Wilson, Fundamentals of Momentum, Heat and Mass Transfer, John Wiley \& Sons, New York, 1969, pg 455.

8. J-P Bonal and D Moulinier, Thermal Properties of Advanced Carbon Fiber Composites for Fusion Application, Commissariat A L'Energie Atomique, Rapport DMT/95-495, October 1995.

9. G.R. Longhurst et. al., Fusion Safety Program Annual Report Fiscal Year 1996, INEEL, INEL-96/0483, pp 11-12, December 1996.

10. T.D. Marshall, R.J. Pawelko, R.A. Anderl, G.R. Smolik, B.J. Merrill, R.L. Moore, Air Chemical Reactivity Measurements of the Carbon Fiber Composite NB31, INEEL, INEEL/EXT-02-00745, May 2002. 
